\title{
Characterization of the In Vitro and In Vivo Efficacy of Baloxavir Marboxil against the H5 Highly Pathogenic Avian Influenza Virus Infection
}

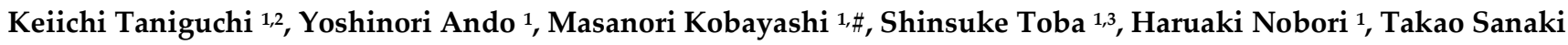 \\ 1, Takeshi Noshi 1, Makoto Kawai 1, Ryu Yoshida 1, Akihiko Sato 1,3, Takao Shishido 1," , Akira Naito 1, Keita \\ Matsuno ${ }^{3,4}$, Masatoshi Okamatsu 2, Yoshihiro Sakoda ${ }^{2,4}$, and Hiroshi Kida ${ }^{3,4}$
}
${ }^{1}$ Shionogi \& Co., Ltd., Osaka, Japan; keiichi.taniguchi@shionogi.co.jp yoshinori.ando@shionogi.co.jp $\underline{\text { rs- }}$ km63@mail.doshisha.ac.jp, shinsuke.toba@shionogi.co.jp haruaki.nobori@shionogi.co.jp, takao.sanaki@shionogi.co.jp, takeshi.noshi@shionogi.co.jp, makoto.kawai@shionogi.co.jp, ryu.yoshida@shionogi.co.jp, akihiko.sato@shionogi.co.jp takao.shishido@shionogi.co.jp, akira.naito@shionogi.co.jp
2 Department of Disease Control, Faculty of Veterinary Medicine, Hokkaido University, Japan; keiichi.taniguchi@shionogi.co.jp, okamatsu@vetmed.hokudai.ac.jp, sakoda@vetmed.hokudai.ac.jp
${ }^{3}$ International Institute for Zoonosis Control, Hokkaido University, Japan; shinsuke.toba@shionogi.co.jp, akihiko.sato@shionogi.co.jp matsuk@czc.hokudai.ac.jp kida@vetmed.hokudai.ac.jp
${ }^{4}$ Global Station for Zoonosis Control, Global Institution for Collaborative Research and Education (GI-CoRE), Hokkaido University, Japan; matsuk@czc.hokudai.ac.jp, sakoda@vetmed.hokudai.ac.jp kida@vetmed.hokudai.ac.jp
* Correspondence: takao.shishido@shionogi.co.jp; Tel: +81-6-6331-7263
"Present address: Organization for Research Initiatives and Development, Doshisha University, Kyoto, Japan

\begin{abstract}
Human infections with the H5 highly pathogenic avian influenza virus (HPAIV) sporadically threatens public health. The susceptibility of HPAIVs to baloxavir acid (BXA), which is a new class of inhibitor for the influenza virus cap-dependent endonuclease, has been confirmed in vitro, but has not yet been characterized fully. Here, the efficacy of BXA against HPAIVs, including recent $\mathrm{H} 5 \mathrm{~N} 8$ variants in vitro was assessed. The antiviral efficacy of baloxavir marboxil (BXM) in H5N1 virus-infected mice was also investigated. BXA exhibited similar in vitro activities against $\mathrm{H} 5 \mathrm{~N} 1, \mathrm{H} 5 \mathrm{~N} 6$, and $\mathrm{H} 5 \mathrm{~N} 8$ variants tested to those of seasonal and other zoonotic strains. BXM monotherapy in mice infected with the H5N1 HPAIV clinical isolate; A/Hong Kong/483/1997 (H5N1) strain, also caused a significant reduction in viral titers in the lungs, brains, and kidneys, followed by prevention of acute lung inflammation and improvement of mortality compared with oseltamivir phosphate (OSP). Furthermore, combination treatments with BXM and OSP, using a 48hour delayed treatment model showed a more potent effect on viral replication in organs, accompanied by improved survival compared to BXM or OSP monotherapy. From each test, no resistant virus (e.g., I38T in the PA) emerged in any BXM-treated mouse. These results therefore support the conclusion that BXM has potent antiviral efficacy against H5 HPAIV infections.
\end{abstract}

Keywords: baloxavir marboxil; H5N1 highly pathogenic avian influenza virus; viral replication; inhibition; lung inflammation; combination therapy; oseltamivir

\section{Introduction}

Since 1997, human infections with H5N1 highly pathogenic avian influenza viruses (HPAIVs) have been reported in Africa, Asia, Europe, and the Middle East with high mortality and morbidity [1,2]. The spread of H5N1 HPAIVs in poultry populations also increases the risk of human infections. Therefore, the emergence of HPAIVs, which is not only evident in poultry, but also in humans, is a major concern for public health [3]. 
Recently, H5N6 HPAIVs sporadically crossed the species barrier and infected humans since 2014 [4]. In 2021, human infection with H5N8 HPAIVs was first reported in Russia [5]. Additionally, human influenza $\mathrm{H} 5 \mathrm{~N} 1$ viral infection has also resulted in severe pneumonia, where most patients died of progressive respiratory failure with acute respiratory distress syndrome (ARDS) [6,7]. H5N1 viruses infect human alveolar epithelial cells (AEC) or alveolar macrophages in the lower respiratory tract as well [8]. The loss of the alveolar barrier function caused by AEC disruption has also been reported to result in severe pneumonia [9]. Levels of proinflammatory cytokines and chemokines, such as interleukin (IL)-6 and monocyte chemoattractant protein (MCP)-1, are a hallmark of $\mathrm{H} 5 \mathrm{~N} 1$ virus infection in the lungs of patients, supporting the hypothesis that a harmful cytokine storm is central to its disease pathogenesis [10]. In a previous report, the reduction in viral titers in the lungs by anti-influenza drug treatments positively correlated with both the suppression of proinflammatory cytokine production and disease severity in an $\mathrm{H} 5 \mathrm{~N} 1$ virus-infected murine model, thereby establishing that a strong inhibition of viral replication can reduce lung dysfunction [11].

Baloxavir marboxil (BXM), which is converted metabolically to its active form; baloxavir acid (BXA), is a first-in-class cap-dependent endonuclease (CEN) inhibitor that has recently been approved for clinical use in over 65 countries in 2021. Notably, BXA exhibits broad antiviral activities against several types and subtypes of influenza viruses, including zoonotic strains in vitro [12-14]. However, BXA's susceptibility to H5 HPAIVs isolated during various seasons, including H5N8 viruses that have recently been isolated, remains unknown. Moreover, BXM showed greater and more rapid reductions in viral load after initiation of the regimen, compared with other anti-influenza drugs in clinical and in vivo non-clinical studies [15-20]. Nevertheless, due to the sporadic presentation of clinical cases, clinical assessments in H5 HPAIV-infected patients are difficult. Therefore, it is beneficial to assess the BXM antiviral effect and regimen using in vivo models.

For treating severe influenza cases, combination therapy using antiviral drugs with different mechanisms of action, provides theoretical benefits [21,22]. Besides, studies have shown that combination therapy with oseltamivir phosphate (OSP) and BXM or favipiravir (FPV) is effective in mice [16,23-25]. In our previous study, the antiviral activity of peramivir in clinical settings, in addition to other neuraminidase inhibitors against the H5N1 HPAIV clinical isolate; A/Hong Kong/483/1997 strain, was evaluated in vivo [11]. However, insufficient therapeutic evidence for combination therapy with BXM and OSP from infected animal models of zoonotic strains exists. We therefore report the antiviral activities of BXM's monotherapy or combination therapy with OSP against A/Hong Kong/483/1997 (H5N1), in vivo.

The HPAIVs are susceptible to neuraminidase inhibitors (NAIs) [26], and treatment with oseltamivir has been reported to be effective in patients with H5N1 HPAIV infections [27]. However, the emergence of drug-resistant mutants (e.g., H274Y in the NA) has been detected after NAI treatment in patients with this virus strain $[28,29]$. These mutations were also observed during animal surveillance studies of circulating H5N1 influenza viruses and have been identified in avian and human isolates as well, including an isolate from a patient treated with oseltamivir [30,31]. Furthermore, in BXM clinical trials, PA amino acid substitutions (e.g., I38T) of seasonal influenza virus strains were detected in some patients after drug administration [13,32-34]. However, no reports of emerging zoonotic strains with reduced BXA susceptibility exist. Hence, it is important to monitor and verify the BXA susceptibility of zoonotic strains in preparation for future emergence. On the basis of the above reasons, viruses harboring the PA amino acid substitution in BXM-treated-mice were also monitored in this study. 


\section{Materials and Methods}

\subsection{Compounds}

Baloxavir marboxil (BXM) and baloxavir acid (BXA) were synthesized at Shionogi \& Co., Ltd. Whereas, oseltamivir acid (OSA) was purchased from Toronto Research Chemicals Inc. (Toronto, Ontario, Canada). Subsequently, OSP was obtained from Sequoia Research Products Ltd. (Pangbourne, UK), peramivir trihydrate (PRV) was purchased from AstaTech, Inc. (Philadelphia, PA, USA), and PharmaBlock Sciences, Inc. (Nanjing, China) supplied favipiravir (FPV).

\subsection{Cells and Viruses}

Madin-Darby canine kidney (MDCK) cells were maintained at $37^{\circ} \mathrm{C}$ under $5 \% \mathrm{CO}_{2}$ in Minimum Essential Media (MEM; Nissui Pharmaceutical) supplemented with 10\% heat-inactivated fetal bovine serum (FBS), $2 \mathrm{mmol} / \mathrm{L}$ L-glutamine, 50 units/mL penicillin, $50 \mu \mathrm{g} / \mathrm{mL}$ streptomycin, and $0.05 \%$ sodium hydrogen carbonate. Then, human lung adenocarcinoma epithelial (A549) cells were maintained at $37^{\circ} \mathrm{C}$ under $5 \% \mathrm{CO}_{2}$ in Dulbecco's Modified Eagle Medium supplemented with 10\% heat-inactivated FBS, 50 units/mL penicillin, and $50 \mu \mathrm{g} / \mathrm{mL}$ streptomycin. Subsequently, the non-mouse adapted avian influenza A/Hong Kong/483/1997 (H5N1) virus, which is a clinical isolate that is pathogenic in mice $[35,36]$, in addition to A/ruddy turnstone/Delaware/103/2007 (H5N1), A/muscovy duck/Vietnam/OIE-559/2011 (H5N1), A/whooper swan/Mongolia/2/2006 (H5N1), A/black swan/Akita/1/2016 (H5N6), A/northern pintail/Hokkaido/M13/2020 (H5N8), A/whooper swan/Fukushima/0701B002/2021 (H5N8), and A/whooper swan/Miyagi/0402B001/2021 (H5N8) strains [37-40] were propagated in embryonated chicken eggs and harvested from virus-containing allantoic fluids. Afterward, recombinant A/Hong Kong/483/1997 (H5N1) viruses (wild-type, harboring NA/H274Y and NA/N294S) were generated via plasmid-based reverse genetics [41]. Next, recombinant viruses were also propagated in embryonated chicken eggs and harvested from virus-containing allantoic fluids, after which infectious titers of all viruses were determined using the standard 50\% tissue culture infectious dose (TCID50) assay in MDCK cells.

\subsection{Viral Yield Reduction Assay}

Two days before infection, MDCK cells were seeded in 96-well plates. These cells were then infected with indicated viruses at 100 TCID $50 /$ well. Subsequently, infected cells were incubated at $35^{\circ} \mathrm{C}$ under $5 \% \mathrm{CO}_{2}$ for one hour. Later, the viral inoculum was washed out, followed by the addition of the fresh medium and definition of the concentrations of test compounds. Afterward, cells were incubated at $35^{\circ} \mathrm{C}$ under $5 \% \mathrm{CO}_{2}$ for $24 \mathrm{~h}$, and viral titers (TCID $50 / \mathrm{mL}$ ) in the culture supernatants were determined in MDCK cells. The effective concentration achieving 90\% (EC90) was finally calculated as the concentration decreasing the viral titers in the culture supernatant to one-tenth of the untreated control values using the linear interpolation method, after which the mean and standard deviation (SD) values were calculated from three independent experiments.

\subsection{Animal Experiments}

\subsubsection{Experiment 1}

Six-week-old female BALB/c mice (Japan SLC, Inc., Shizuoka, Japan) were maintained in a controlled temperature environment and humidity. Mice were then infected intranasally with 75 TCID $_{50}$ (31.3 of 50\% mouse lethal dose [MLD50]) of the A/Hong Kong/483/1997 (H5N1) virus, and treatment started immediately after viral inoculation. Subsequently, mice were treated with BXM $(0.5 \mathrm{mg} / \mathrm{kg} / \mathrm{dose}, 5 \mathrm{mg} / \mathrm{kg} / \mathrm{dose}$, or $50 \mathrm{mg} / \mathrm{kg} /$ dose) twice daily (12-h interval between each dosing) for one or five day(s) 
through oral gavage. The dosing regimen of BXM, which was at $5 \mathrm{mg} / \mathrm{kg} / \mathrm{dose}$, twice daily for five days, is an extrapolated clinical setting from our previous mice models $[18,19]$. However, for the controls, vehicle $(0.5 \mathrm{w} / \mathrm{v} \%$ methylcellulose) or OSP $(5 \mathrm{mg} / \mathrm{kg} / \mathrm{dose}$ [clinically-equivalent dose; $75 \mathrm{mg} / \mathrm{kg} /$ day [42]] or $50 \mathrm{mg} / \mathrm{kg} / \mathrm{dose}$ ) was administered twice daily for five days through oral gavage. Dosing volume was $10 \mathrm{~mL} / \mathrm{kg}$ calculated by body weight before each dosing. Survival rates and body weight changes were then monitored through a 14-day period after the infection ( $n=10$ /group). Viral titers in the lungs of mice at one, three, and five days post infection (dpi) were finally determined in MDCK cells ( $\mathrm{n}$ $=5 /$ group), while viral titers in the brains and kidneys of mice at $6 \mathrm{dpi}$ were determined in MDCK cells ( $\mathrm{n}=5$ /group).

\subsubsection{Experiment 2}

Mice were infected intranasally with $75 \mathrm{TCID}_{50}\left(31.3 \mathrm{MLD} \mathrm{D}_{50}\right.$ ) of the A/Hong Kong/483/1997 (H5N1) virus, and treatment started $48 \mathrm{~h}$ after viral inoculation. Mice were treated with BXM ( 5 or $50 \mathrm{mg} / \mathrm{kg} /$ dose) twice daily for five days through oral gavage. For the controls, the oral gavage method was used to administer the vehicle or OSP (10 $\mathrm{mg} / \mathrm{kg} / \mathrm{dose}$ ) twice daily for five days. Combination therapy was then conducted with BXM $(5 \mathrm{mg} / \mathrm{kg})$ and OSP $(10 \mathrm{mg} / \mathrm{kg})$ twice daily for five days through oral gavage. Dosing volume was $10 \mathrm{~mL} / \mathrm{kg}$ calculated by body weight before each dosing. Afterward, survival rates and body weight changes were monitored through a 21-day period after the infection ( $n=5 /$ group). Then, viral titers in the lungs, brains, and kidneys of mice at 3, 5, 6 , and 7 dpi were determined in MDCK cells ( $n=5 /$ group).

During all experiments, animals were housed in self-contained units (Tokiwa Kagaku, Tokyo, Japan) at the BSL-3 and ABSL-3 facilities of the Faculty of Veterinary Medicine, Hokkaido University, Japan. Additionally, animal experiments were conducted, following the guidelines of the institutional animal care and use committee of Hokkaido University (approval number 15-0063, 15-0067, 15-0068, and 18-0107). Mice were euthanized when they lost greater than $30 \%$ of their body weight compared with their pre-infection weight.

\subsection{Sequence Analysis of the PA or NA Region}

\subsubsection{Experiment 1}

Viral RNAs derived from lung homogenates of BXM-treated mice were extracted using a QIAamp ${ }^{\circledR}$ Viral RNA Mini Kit (QIAGEN) according to the manufacturer's protocol. Then, quantitative real-time polymerase chain reaction (Real-Time RT-PCR) was used to quantify the obtained samples. Subsequently, Sanger sequencing was used to conduct sequence analysis of PA region (the PA gene of A/Hong Kong/483/1997 [H5N1] strain). All RNA samples quantified over the lower limit of quantification (800 copies/reaction) were subject to this analysis. Also, LSI Medience Corporation conducted Real-Time RT-PCR and Sanger sequencing.

\subsubsection{Experiment 2}

Viral RNA samples derived from lung homogenates of BXM-treated mice were extracted using a QIAamp ${ }^{\circledR}$ Viral RNA Mini Kit (QIAGEN) according to the manufacturer's protocol. Next-generation sequencing and analysis were then conducted as previously reported [43], after which amino acid substitutions of viruses were detected using the low frequency variant detection method of CLC Genomic Workbench (CLC bio, Aarhus, Denmark). Sequencing coverage for variant detection of this test was more than 10 -fold depth, and the percentage of reads with a quality score greater than 30 was $70 \%$.

\subsection{Quantitative Analysis of Proinflammatory Cytokines and Chemokines}

Levels of interleukin (IL)- 6 and monocyte chemoattractant protein (MCP)-1 in the lungs were quantitatively determined using Quantikine ELISA (R\&D Systems). Lung samples were then collected from viral titer experiments infected with 75 TCID 50 of the 
A/Hong Kong/483/1997 (H5N1) strain at 5 dpi (experiment 1). Next, collected lungs were homogenized, after which each sample was processed according to the manufacturer's protocol.

\subsection{Histopathological Experiments}

Lungs were collected from mice infected with $75 \mathrm{TCID}_{50}$ of the A/Hong Kong/483/1997 (H5N1) strain at 5 dpi ( $n=3 /$ group). Then, the samples were fixed through perfusion in $10 \%$ phosphate-buffered formalin. Formalin-fixed left lungs were subsequently dissected, embedded in paraffin, and sectioned. Finally, hematoxylin and eosin (HE) staining sections were prepared for the specimen, after which Sapporo General Pathology Laboratory Co., Ltd. (Sapporo, Japan) conducted histopathological analysis.

\subsection{Assessment of Lung Index}

Body weights of mice infected with 75 TCID 50 of the A/Hong Kong/483/1997 (H5N1) strain were measured, then the lungs were collected at $5 \mathrm{dpi}(\mathrm{n}=5 /$ group). Whole lungs were then weighed, after which the lung's wet weight-to-body weight ratios in each treatment group was calculated as previously reported [44].

\subsection{Combined Effects of Baloxavir Acid and NAIs In Vitro}

A549 cells, the A/Hong Kong/483/1997 (H5N1) virus (319 TCID50/well), and compounds in serial dilutions (for BXA, 0.1 to $8.0 \mathrm{nmol} / \mathrm{L}$; for OSA, 1.6 to $400 \mathrm{nmol} / \mathrm{L}$; for peramivir trihydrate, 1.6 to $100 \mathrm{nmol} / \mathrm{L}$ ), were simultaneously seeded in 96-well plates. The infected cells were then incubated at $37^{\circ} \mathrm{C}$ under $5 \% \mathrm{CO}_{2}$ for four days. All supplements were prepared using 2\% FBS in MEM. After incubation, cell viability was then assessed with an MTT reagent as previously reported [45]. Afterward, data analysis for yielding isobologram plots and calculating the combination index $(\mathrm{CI})$ values was conducted as previously reported [16].

\subsection{Statistical Analysis}

For comparing the survival periods after infection between each BXM-treated group or BXM/OSP combination group and vehicle-treated or OSP-treated groups, the log-rank test was applied. However, for comparing between viral titers in mouse tissues, cytokine and chemokine levels in lung tissue, lung wet weight-to-body weight ratios between each BXM-treated group, or between the BXM/OSP combination group and vehicle-treated or OSP-treated groups at each time, Dunnett's multiple-comparison method was used. All statistical analysis was conducted using the statistical analysis software SAS version 9.2 for Windows (SAS Institute, Cary, NC). $P$ values $<0.05$ were considered statistically significant.

\subsection{Ethics Statement}

The animal experiments were authorized by the Institutional Animal Care and Use Committee of the Faculty of Veterinary Medicine, Hokkaido University (approval numbers 15-0063, approved on 1 June 2015, 15-0067, approved on 11 June 2015, 15-0068, approved on 11 June 2015 and 18-0107, approved on 23 July 2018), and performed according to the guidelines of this committee. The facilities where the animal experiments were conducted are certified by the Association for Assessment and Accreditation of Laboratory Animal Care International (AAALAC International). 


\section{Results}

\subsection{Inhibitory Effects of BXA on H5 HPAIV Replication In Vitro}

To examine the antiviral activity of BXA against H5 HPAIVs, including recently isolated $\mathrm{H} 5 \mathrm{~N} 8$ variants, in vitro drug susceptibility of BXA was evaluated. BXA showed comparable inhibition efficacy in tested viruses (mean EC90 ranged from 0.7 to $1.5 \mathrm{nmol} / \mathrm{L}$ ), compared to that of A/Hong Kong/483/1997 (H5N1) and other H5 (the mean EC90 of 0.7 to $1.6 \mathrm{nmol} / \mathrm{L}$ ) viruses as previously reported (Table 1) [12]. Moreover, BXA also showed inhibitory activities against viruses harboring the NA-H274Y and NA-N294S substitution, which has been related to OSA resistance [28,46]. In contrast, OSA required approximately 14-fold or higher concentrations to accomplish similar levels of viral reduction than BXA. However, FPV showed comparable antiviral activity to the tested viruses, but the concentration range of FPV used remained higher than that of BXA. These results therefore demonstrate that BXA had more potent antiviral activities in vitro compared to OSA and FPV against H5 HPAIVs. Since all tested viruses had comparable susceptibility to BXA, the A/Hong Kong/483/1997 (H5N1) strain was selected for subsequent analyses.

Table 1 Antiviral activities of baloxavir acid and other reference compounds against HPAIV in viral yield reduction assay

\begin{tabular}{|c|c|c|c|c|c|c|c|c|c|}
\hline \multirow{3}{*}{\begin{tabular}{l}
\multicolumn{1}{c}{ Influenza virus strains } \\
A/ruddy turnstone/Delaware/103/2007 \\
(H5N1)
\end{tabular}} & \multicolumn{9}{|c|}{ Mean EC $90(\mathrm{nmol} / \mathrm{L}) \pm \mathrm{SD}$} \\
\hline & \multicolumn{3}{|c|}{ Baloxavir acid } & \multicolumn{3}{|c|}{ Oseltamivir acid } & \multicolumn{3}{|c|}{ Favipiravir } \\
\hline & 1.4 & \pm & 1.3 & 12.8 & \pm & 5.7 & 16927.4 & \pm & 12375.0 \\
\hline $\begin{array}{l}\text { A/muscovy duck/Vietnam/OIE-559/2011 } \\
\text { (H5N1) }\end{array}$ & 1.5 & \pm & 0.3 & 20.7 & \pm & 10.9 & 11689.6 & \pm & 7333.8 \\
\hline A/whooper swan/Mongolia/2/2006 (H5N1) & 0.9 & \pm & 0.5 & 14.9 & \pm & 1.6 & 13812.0 & \pm & 11056.8 \\
\hline A/black swan/Akita/1/2016 (H5N6) & 0.8 & \pm & 0.5 & 20.0 & \pm & 9.7 & 50156.1 & \pm & 69943.5 \\
\hline $\begin{array}{l}\text { A/northern pintail/Hokkaido/M13/2020 } \\
\text { (H5N8) }\end{array}$ & 1.3 & \pm & 1.0 & 19.5 & \pm & 11.9 & 16025.5 & \pm & 10164.5 \\
\hline $\begin{array}{l}\text { A/whooper swan/Fukushima/0701B002/2021 } \\
\text { (H5N8) }\end{array}$ & 1.1 & \pm & 1.0 & 19.2 & \pm & 13.9 & 16052.1 & \pm & 12507.3 \\
\hline $\begin{array}{l}\text { A/whooper swan/Miyagi/0402B001/2021 } \\
\text { (H5N8) }\end{array}$ & 0.7 & \pm & 0.3 & 11.3 & \pm & 2.8 & 6992.6 & \pm & 1370.8 \\
\hline rg-A/Hong Kong/483/1997 (H5N1) & 1.6 & \pm & 1.0 & 16.4 & \pm & 11.4 & 26948.7 & \pm & 5081.5 \\
\hline rg-A/Hong Kong/483/1997 NA-H274Y & 3.2 & \pm & 1.2 & 4054.9 & \pm & 1295.7 & 31129.5 & \pm & 11788.5 \\
\hline rg-A/Hong Kong/483/1997 NA-N294S & 1.7 & \pm & 0.4 & 1291.2 & \pm & 482.6 & 77002.6 & \pm & 2190.5 \\
\hline
\end{tabular}

Each value represents the mean and SD for 3 independent experiments.

\subsection{The Protective Efficacy of BXM on Lethal H5N1 HPAIV Infections In Vivo}

To evaluate the effects of oral BXM (prodrug form of BXA) against H5N1 HPAIVs in a lethal infection model, mice were inoculated with 31.3 MLD50 of the A/Hong Kong/483/1997 (H5N1) strain. Vehicle- or clinically-equivalent doses of OSP $5 \mathrm{mg} / \mathrm{kg} / \mathrm{dose}$ administered twice daily for five days [42]-treated mice died within seven and nine days post infection (dpi), respectively (Fig. 1). In contrast, supratherapeutic doses of OSP 50 $\mathrm{mg} / \mathrm{kg} /$ dose, which was administered twice daily for five days, resulted in $70 \%$ survival. In this setting, survival rates of BXM administered at $0.5,5$, and $50 \mathrm{mg} / \mathrm{kg}$, twice daily for one day were $20 \%, 100 \%$, and $100 \%$, respectively. All mice survived after treatment using BXM, which was administered at 5 and $50 \mathrm{mg} / \mathrm{kg}$ for five days. This result was consistent with that obtained from other subtype-infected mice as previously reported $[18,19]$. Compared to the survival time for $14 \mathrm{dpi}$, all mice treated with BXM showed significantly prolonged survival times compared with those administered the vehicle $(p<0.001$ in all groups) or OSP at $5 \mathrm{mg} / \mathrm{kg}$ ( $p<0.01$ [only $0.5 \mathrm{mg} / \mathrm{kg}$ twice a day for 1 day], $p<0.001$, respectively). However, although gradual body weight loss after virus infection was 
observed in the vehicle-treated mice until 6 dpi (Fig. S1), BXM strongly prevented body weight loss, when compared to vehicle and OSP treated groups.

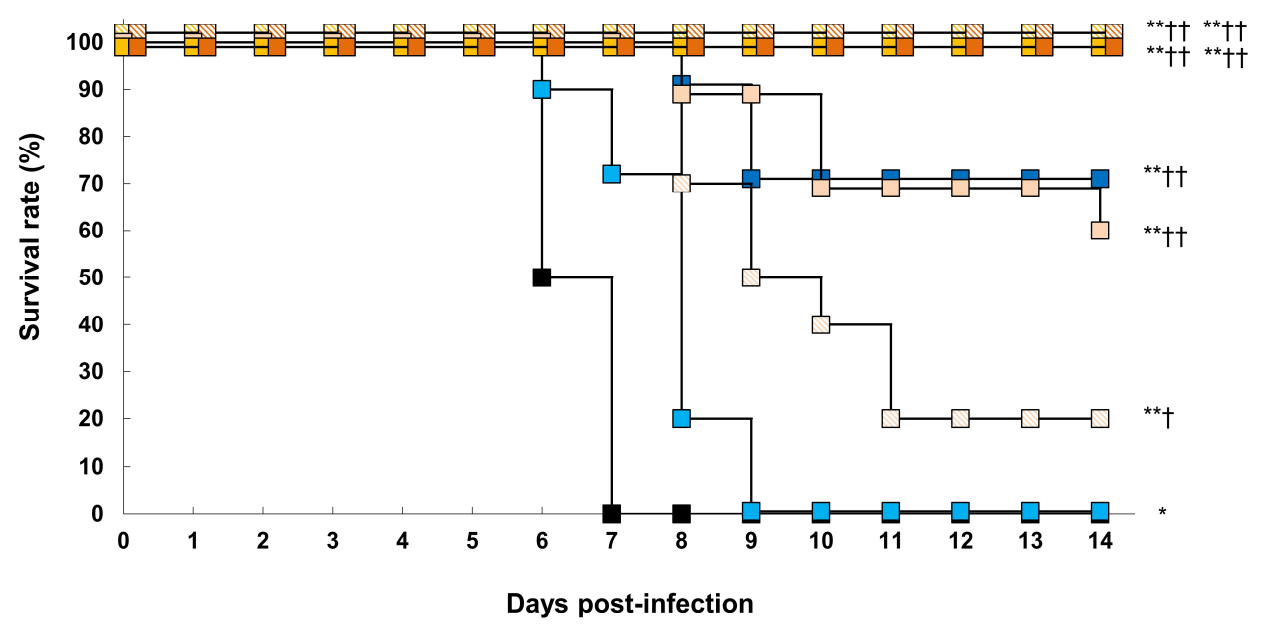

$\square$ Vehicle

BXM $0.5 \mathrm{mg} / \mathrm{kg}$ bid for 1 day

OSP $5 \mathrm{mg} / \mathrm{kg}$ bid for 5 days $\square$ OSP $50 \mathrm{mg} / \mathrm{kg}$ bid for 5 days

$\square$ BXM $0.5 \mathrm{mg} / \mathrm{kg}$ bid for 5 days

$\mathbb{B}$ BXM $5 \mathrm{mg} / \mathrm{kg}$ bid for 1 day $\mathbb{B}$ BXM $50 \mathrm{mg} / \mathrm{kg}$ bid for 1 day

$\square$ BXM $5 \mathrm{mg} / \mathrm{kg}$ bid for 5 days $\square$ BXM $50 \mathrm{mg} / \mathrm{kg}$ bid for 5 days

Figure 1. Therapeutic effects of BXM on survival in a lethal infection model of mice infected with H5N1 virus

Mice were intranasally inoculated with 75 TCID50/mouse (31.3 MLD50) of the A/Hong Kong/483/1997 (H5N1) virus, and treatment started immediately after viral inoculation ( $\mathrm{n}=$ 10/group). Survival time was then monitored through a 14-day period after the infection. The logrank test was applied to compare the survival time between each group $\left({ }^{*} p<0.01,{ }^{* *}, p<0.001\right.$ compared to the vehicle, $+p<0.01,+\dagger p<0.001$ compared to OSP at $5 \mathrm{mg} / \mathrm{kg}$ twice daily).

\subsection{Effects of BXM on Viral Titers in Mice Infected With H5N1 HPAIVs}

To examine the inhibitory effects of BXM on H5N1 HPAIV, replication, viral titers in the lung homogenate derived from A/Hong Kong/483/1997 (H5N1)-infected mice were measured at one, three, and five dpi. OSP treatment decreased viral titers in the lungs of mice compared to that of vehicle treatment at $1 \mathrm{dpi}$. However, this effect diminished in effectiveness at three and five dpi (Fig. 2a). In contrast, BXM treatments significantly decreased viral titers in the lungs of mice compared to that of vehicle- or OSP-treated mice at one dpi $(p<0.001$ in all BXM-treated mice compared to the vehicle and $p<0.01$ in all BXM-treated mice compared to OSP at $5 \mathrm{mg} / \mathrm{kg}$ ), and repeated BXM treatments at 3 and 5 dpi sustained this effectiveness. Notably, BXM treatment at $50 \mathrm{mg} / \mathrm{kg}$ strongly reduced viral titers below the lower limit of quantification $\left(1.5 \log _{10}\right.$ TCID $\left.50 / \mathrm{mL}\right)$ till 5 dpi. Nevertheless, although gradual increases in viral titers for 1-day dosing of BXM at 0.5 $\mathrm{mg} / \mathrm{kg}$ were observed after the withdrawal of treatment, virus titers were suppressed to more than three or four-logs through 1-day dosing of BXM at 5 and $50 \mathrm{mg} / \mathrm{kg}$ compared with that of the vehicle-treatment group.

Additionally, genotypic alterations in the whole PA gene of A/Hong Kong/483/97 (H5N1) derived from lung homogenates of infected mice treated with 1 and 5-day dosing 
of BXM were analyzed. In these lung samples, no mutation in the PA amino acid sequence of the virus was detected. However, in H5N1 HPAIV-infected mice model, infectious viruses were detected in organs other than respiratory tissues (e.g., brain, kidney), which is proposed to be due to spillover of high viral titers of the virus replicated in mice $[47,48]$. Therefore, to confirm the results, we also analyzed the inhibitory effects on viral titers in the brain and kidney homogenate at 6 dpi after viruses had clearly been isolated [47-49]. We observed that infectious viruses were detected in the brain of all vehicle-treated mice (Fig. 2b). Infectious viruses were also detected in the brain samples of three of five $5 \mathrm{mg} / \mathrm{kg}$ OSP -treated mice, one of five $50 \mathrm{mg} / \mathrm{kg}$ OSP-treated mice, and in the brain samples subjected to the one-day dosing of BXM at $0.5 \mathrm{mg} / \mathrm{kg}$-treated. In contrast, no virus was detected in the brain of any 5 and $50 \mathrm{mg} / \mathrm{kg}$ - BXM-treated mice. However, infectious viruses in the kidney were detected only in vehicle-treated mice (Fig. 2c).

\section{(A) Lung}
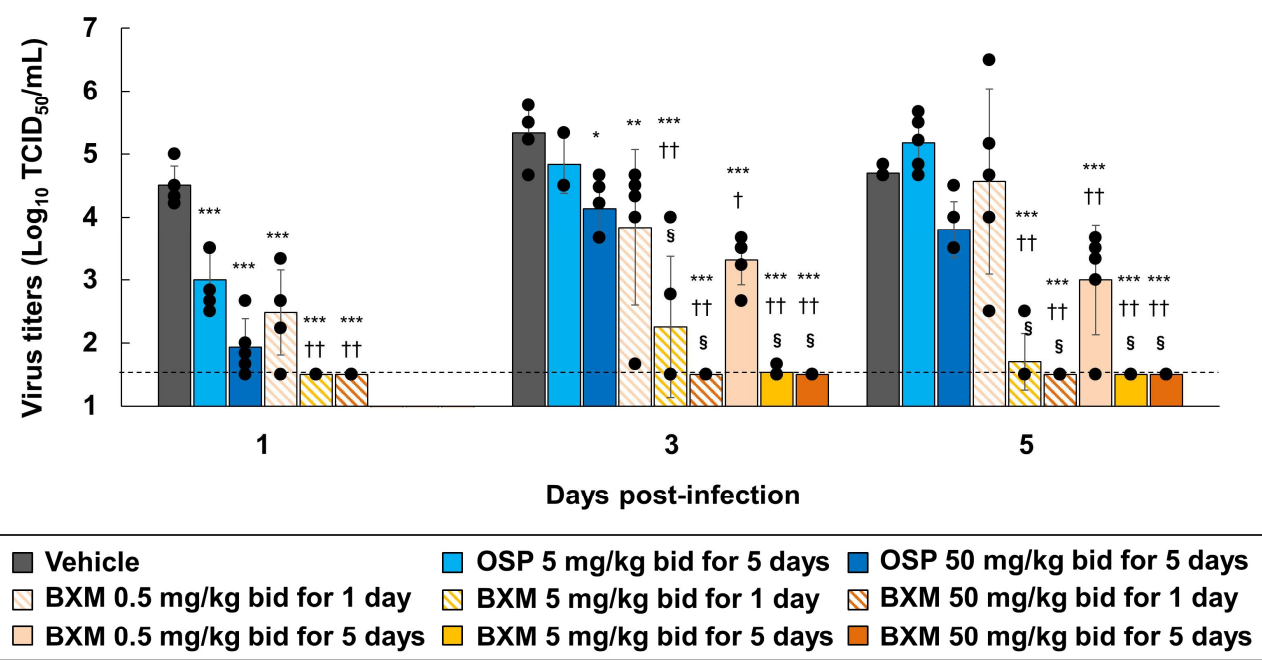

$\square$ OSP $5 \mathrm{mg} / \mathrm{kg}$ bid for 5 days $\square$ OSP $50 \mathrm{mg} / \mathrm{kg}$ bid for 5 days BXM $5 \mathrm{mg} / \mathrm{kg}$ bid for 1 day $\triangle B X M 50 \mathrm{mg} / \mathrm{kg}$ bid for 1 day BXM 0.5 mg/kg bid for 5 days

(B) Brain

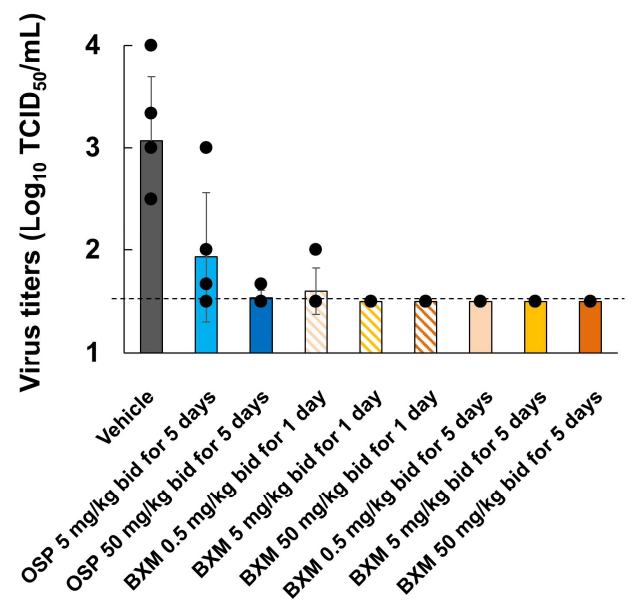

(C) Kidney

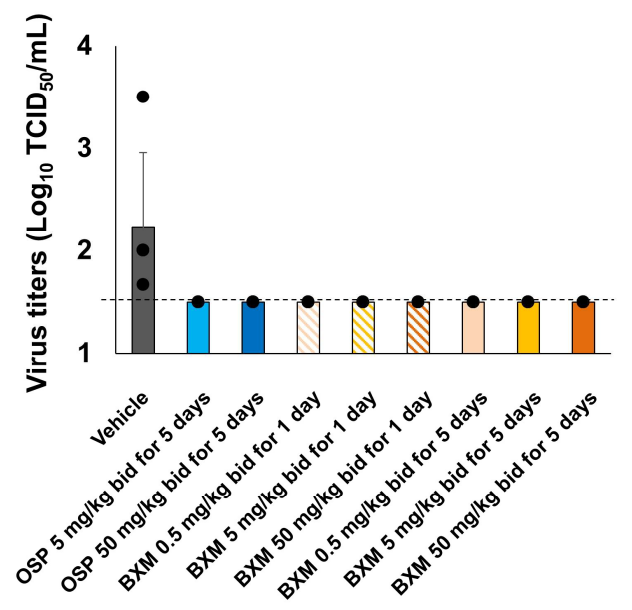


Figure 2. Inhibitory effects of BXM on viral titers in the lungs, brains, or kidneys of mice infected with the $\mathrm{H} 5 \mathrm{~N} 1$ virus

Mice were inoculated with 75 TCID50/mouse (31.3 MLD50) of the A/Hong Kong/483/1997 (H5N1) virus, and treatment started immediately after viral inoculation ( $n=5 /$ group). (a) The viral titers (TCID 50 ) in mice lungs at 1,3 , and 5 dpi measured in MDCK cells. $(\mathbf{b}, \mathbf{c})$ The viral titers in mice brains or kidneys at 6 dpi measured in MDCK cells. The lower limit of quantification of the viral titer was indicated using a dotted line $\left(1.5 \log _{10} \mathrm{TCID}\right.$ 50/mL). Dunnett's multiple-comparison also method was conducted for statistical comparison of viral titers in the lungs between each group ${ }^{*}$ $p<0.05,{ }^{* *} p<0.01,{ }^{* * *}, p<0.001$ compared to the vehicle. $+p<0.01,++p<0.001$ compared to OSP at $5 \mathrm{mg} / \mathrm{kg}$ twice daily. $\S p<0.001$ compared to OSP at $50 \mathrm{mg} / \mathrm{kg}$ twice daily).

\subsection{Prevention of Inflammation in Mice Lungs Following BXM Treatment}

The impact of BXM treatments on inflammation in mice inoculated with $\mathrm{A} / \mathrm{Hong}$ Kong/483/1997 (H5N1) at five dpi was subsequently evaluated. Treatment of the H5N1 virus-infected mice with BXM resulted in a significantly less-pronounced production of IL-6 and MCP-1 compared with vehicle or OSP-treated ones at $5 \mathrm{mg} / \mathrm{kg}$-received mice $(p$ $<0.01$ in all BXM-treated groups compared with vehicle and $p<0.05$ in BXM-treated groups except 1-day dosing at $0.5 \mathrm{mg} / \mathrm{kg}$ compared to OSP at $5 \mathrm{mg} / \mathrm{kg}$ ), which resulted from the reduction of viral titers in mice lungs at $5 \mathrm{dpi}$ (Fig. 3a). OSP treatment also showed a significant inhibitory effect on IL-6 and MCP-1 production in mice lungs compared with the vehicle-treated mice. Subsequent analyses of proinflammatory cytokine and chemokine production in lungs, including histopathological findings from lungs treated with BXM were observed next. Acute pneumonia, including thickening and inflammatory cell infiltration of alveolar walls, inflammatory cell infiltration within the alveoli, bronchiolar and perivascular cell infiltration, in addition to edema was observed in roughly about quarter to half of the global area of all vehicle-treated mice lungs (Fig. $3 \mathrm{~b}$ and Fig. S2). These findings were mildly observed in mice, treated with OSP at $5 \mathrm{mg} / \mathrm{kg}$ for five days compared to the vehicle. In contrast, no abnormal findings in the lungs were observed in each lung after BXM at $5 \mathrm{mg} / \mathrm{kg}$ for 5 days. In our model, the lung weight-tobody ratio of vehicle-treated mice was higher than that of the uninfected control at $5 \mathrm{dpi}$ (Fig. S3). Likewise, the ratios of all groups treated with BXM and OSP were significantly lower than those of vehicle-treated groups. Results also showed that the ratio of groups treated with BXM at 5 and $50 \mathrm{mg} / \mathrm{kg}$ was significantly lower than that treated with OSP at $5 \mathrm{mg} / \mathrm{kg}(p<0.05)$. 
(A)

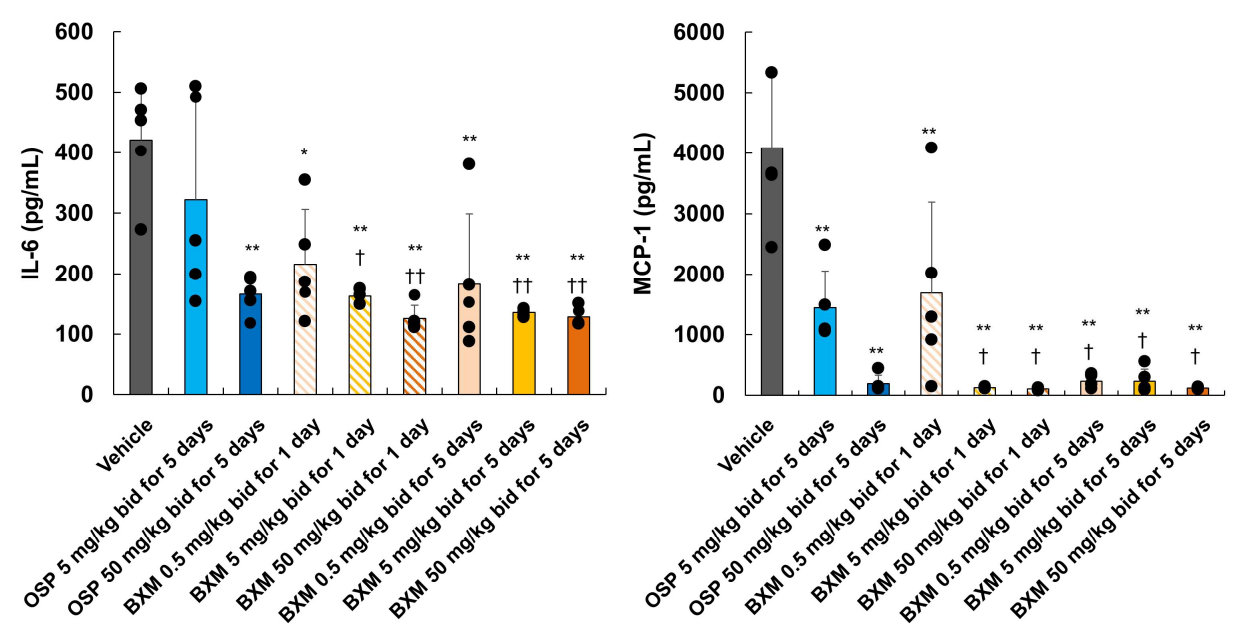

(B)
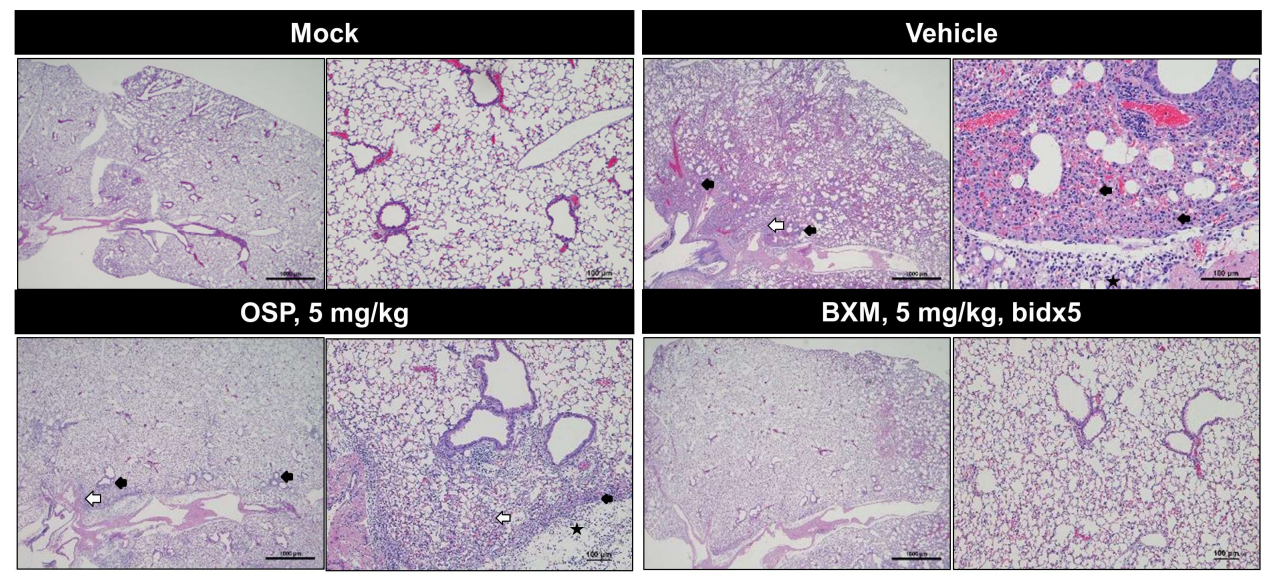

Figure 3. Prevention of inflammation in the lungs of mice infected with H5N1 viruses following BXM treatment

Mice were intranasally infected with 75 TCID50/mouse (31.3 MLD50) of A/Hong Kong/483/1997 (H5N1) virus, after which treatment started immediately after viral inoculation ( $n=5 /$ group). (a) IL-6 and MCP-1 production in the lungs at 5 dpi were then quantified. Dunnett's multiplecomparison method was conducted for the statistical comparison of IL- 6 and MCP-1 production between each group $\left({ }^{*} p<0.01,{ }^{* *}, p<0.001\right.$ compared to the vehicle. $+p<0.05,++p<0.01$ compared to OSP at $5 \mathrm{mg} / \mathrm{kg}$ twice daily). (b) The lungs after each dosing were collected and fixed in perfusion, containing $10 \%$ phosphate-buffered formalin. The formalin-fixed left lungs were then dissected, embedded in paraffin, and sectioned. Hematoxylin and eosin (HE) stained sections, which were prepared for specimen and histopathological findings were subsequently analyzed. Left panels of each dosing showed wide-fields (2× magnification of objective), whereas right panels of each dosing showed narrow-fields (20× magnification of objective). Black arrows indicated thickening and inflammatory cell infiltration of alveolar walls. White arrows indicated inflammatory cell infiltration within the alveoli. Black stars indicated edema. 


\subsection{Combination Efficacy of BXM and NAIs on H5N1 Viral Infections}

BXM monotherapy results were expected to be effective with delayed treatment onset. However, previous studies have inferred that the effects of BXM were attenuated as previously reported [19]. Therefore, the combined efficacy of BXM and OSP in H5N1 virus-infected mice was evaluated to explore the possibilities of a potent therapeutic option than BXM monotherapy as a previous report [16]. First, we evaluated combination effects of BXA and NAIs (OSA or PRV) on the H5N1 viral infection. The CPE assay was then conducted in A549 cells. The isobologram plot showed that combinations of BXA with OSA and PRV resulted in CI values of 0.19 and 0.40 , respectively, indicating that BXA exhibited synergistic effects with NAIs in vitro (Fig. 4) [16,50]. Next, to investigate the therapeutic effect of the BXM monotherapy ( 5 or $50 \mathrm{mg} / \mathrm{kg} /$ dose twice a day for 5 days) or its combination efficacy at clinically higher doses of OSP [51] (5 and $10 \mathrm{mg} / \mathrm{kg} / \mathrm{dose}$ twice a day for 5 days), A/Hong Kong/483/1997 (H5N1)-infected mice were treated, starting $48 \mathrm{~h}$ after infection. All vehicle and OSP treatments at $10 \mathrm{mg} / \mathrm{kg} /$ dose-treated mice showed gradual body weight loss after viral infection, resulting in death within $8 \mathrm{dpi}$ (Fig. 5). BXM at $5 \mathrm{mg} / \mathrm{kg} /$ dose-treated mice also showed delayed body weight loss. However, $40 \%$ survived at $21 \mathrm{dpi}$. Additionally, BXM at $50 \mathrm{mg} / \mathrm{kg} /$ dose showed little body weight loss in treated mice and survived. In this setting, results confirmed that BXM (5 $\mathrm{mg} / \mathrm{kg} / \mathrm{dose})$ and OSP $(10 \mathrm{mg} / \mathrm{kg} / \mathrm{dose})$ treatment suppressed body weight loss and improved survival at 21 dpi compared with monotherapy (Fig. 5). Furthermore, all BXM monotherapy groups significantly decreased viral titers in the lungs of mice compared to that of vehicle- and OSP-monotherapy groups ( $p<0.001$ in all groups) (Fig. 6a). Notably, BXM and OSP combined therapies also reduced viral titers in the lungs and tended to reduce viral titers at 6 and $7 \mathrm{dpi}$ more than those of BXM at $5 \mathrm{mg} / \mathrm{kg} / \mathrm{dose}$ monotherapy. Results further showed that BXM monotherapy or BXM and OSP combination therapies was significantly reduced in the brain and kidney virus titers at 5, 6, and $7 \mathrm{dpi}$ compared to vehicle or OSP monotherapy (Figs. 6b, 6c). Especially, no virus was detected in the kidneys of all BXM treatment groups. Besides, mutation analyses of whole PA and NA genes of the A/Hong Kong/483/1997 (H5N1) viral strain derived from lung homogenate treated with BXM and OSP showed no mutation in PA or NA amino acid sequences, such as I38T mutations in PA or H274Y in NA (Table S1). 

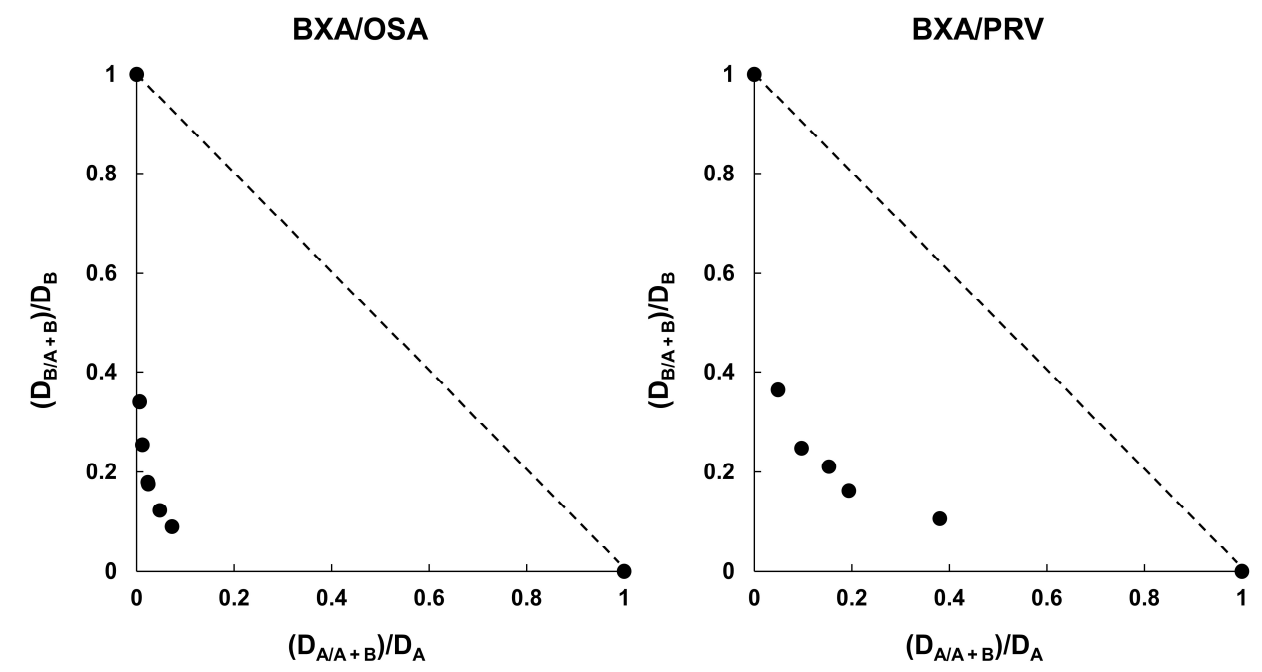

Figure 4. The isobologram plot of BXA combined with OSA or PRV

$\mathrm{EC}_{50}$ of each substance alone and at a fixed concentration were determined. $\left(\mathrm{D}_{\mathrm{A}} / \mathrm{A}+\mathrm{B}\right) / \mathrm{D}_{\mathrm{A}}$ and $\left(D_{B} / A+B\right) / D_{в}$ were plotted on the $x$ - and $y$-axes, respectively. $D_{A}$ is the $E_{50}$ of substance $A$ alone, $D_{\text {в }}$ is the $\mathrm{EC}_{50}$ of substance $\mathrm{B}$ alone, $\mathrm{D}_{\mathrm{A} / \mathrm{A}+\mathrm{B}}$ is the concentration of substance $\mathrm{A}$; given $50 \%$ inhibition combined with substance $B$, and $D_{B} / A+B$ is the concentration of substance $B$; given $50 \%$ inhibition combined with substance A. OSA, oseltamivir acid; PRV, peramivir trihydrate. 
(A)

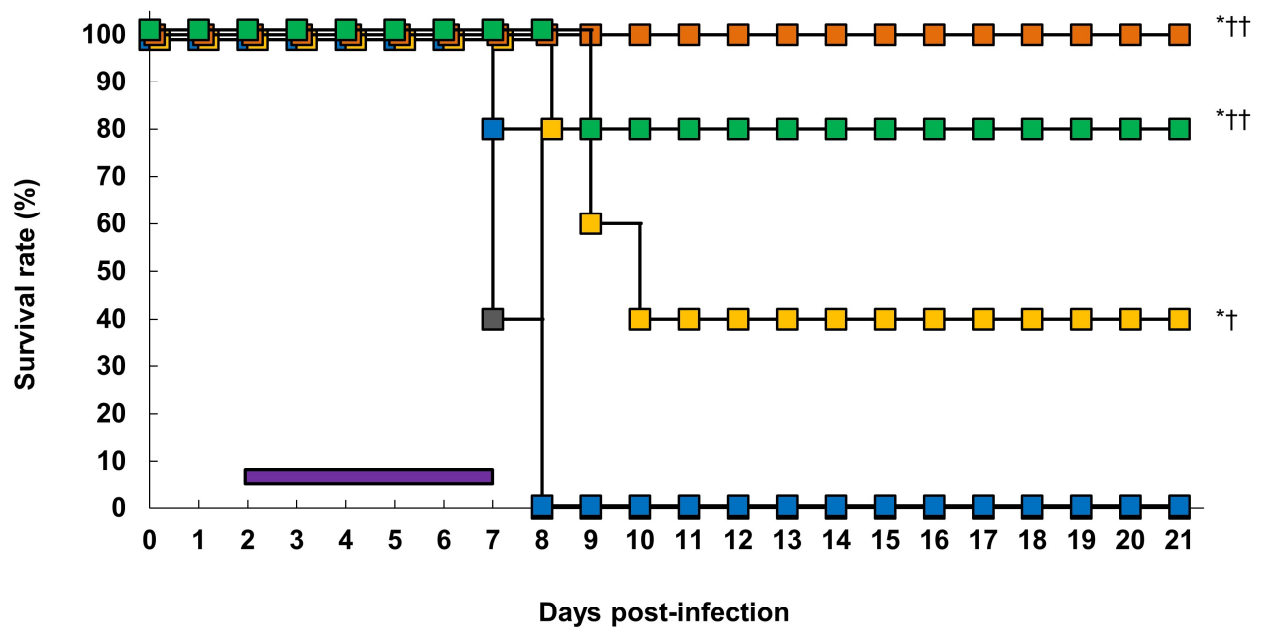

(B)
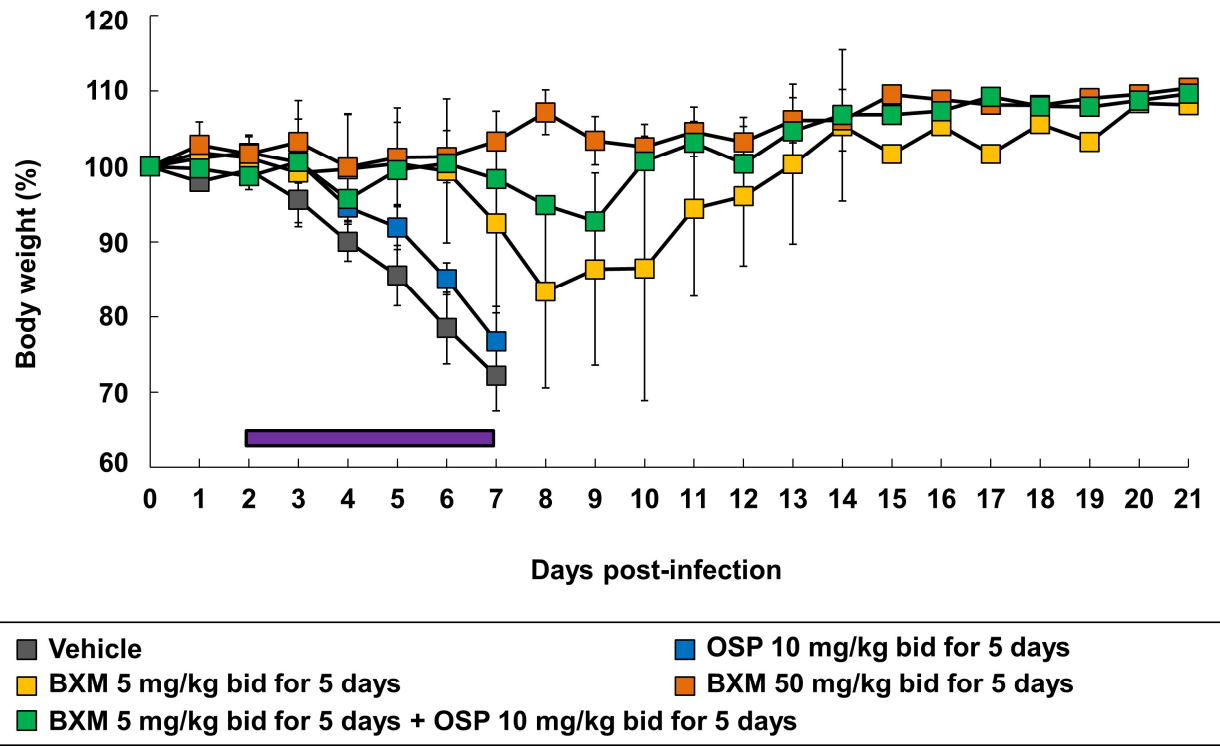

Figure 5. Effects of the delayed treatment of BXM, OSP, or their combination on H5N1 HPAIV infection in the mice model

Mice were intranasally infected with 75 TCID50/mouse (31.3 MLD50) of A/Hong Kong/483/1997 (H5N1) virus, after which treatment started $48 \mathrm{~h}$ after viral inoculation. (a) Survival time and (b) body weight loss was monitored through a 21-day period after the infection ( $n=5 /$ group). The purple line represents the treatment period. The log-rank test was applied for comparison of the survival time between each group $\left({ }^{*} p<0.01\right.$ compared to the vehicle. $+p<0.05$, $++p<0.01$ compared to OSP at $10 \mathrm{mg} / \mathrm{kg}$ twice daily). 
(A) Lung

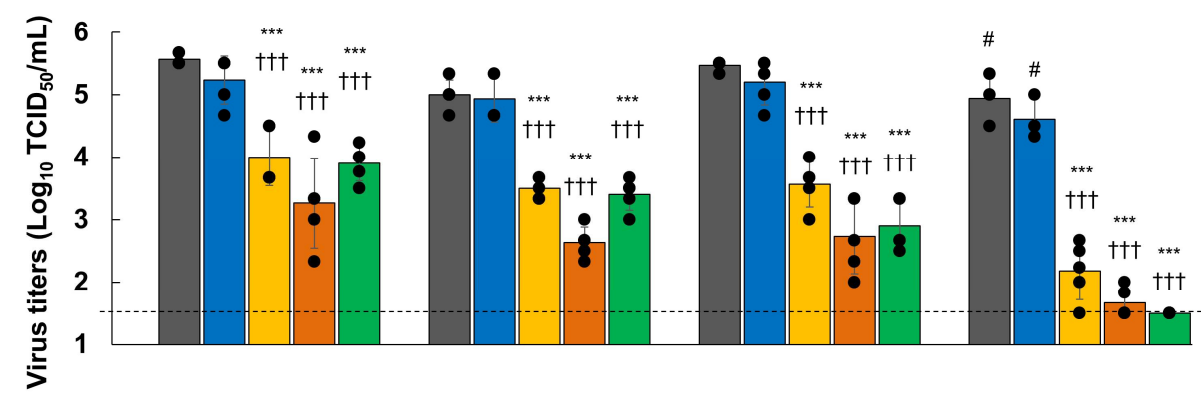

\section{(B) Brain}

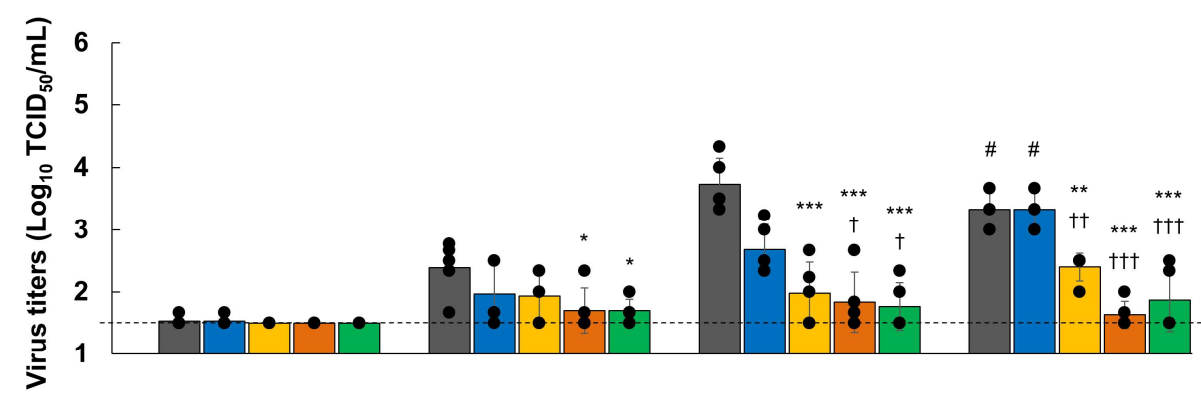

\section{(C) Kidney}
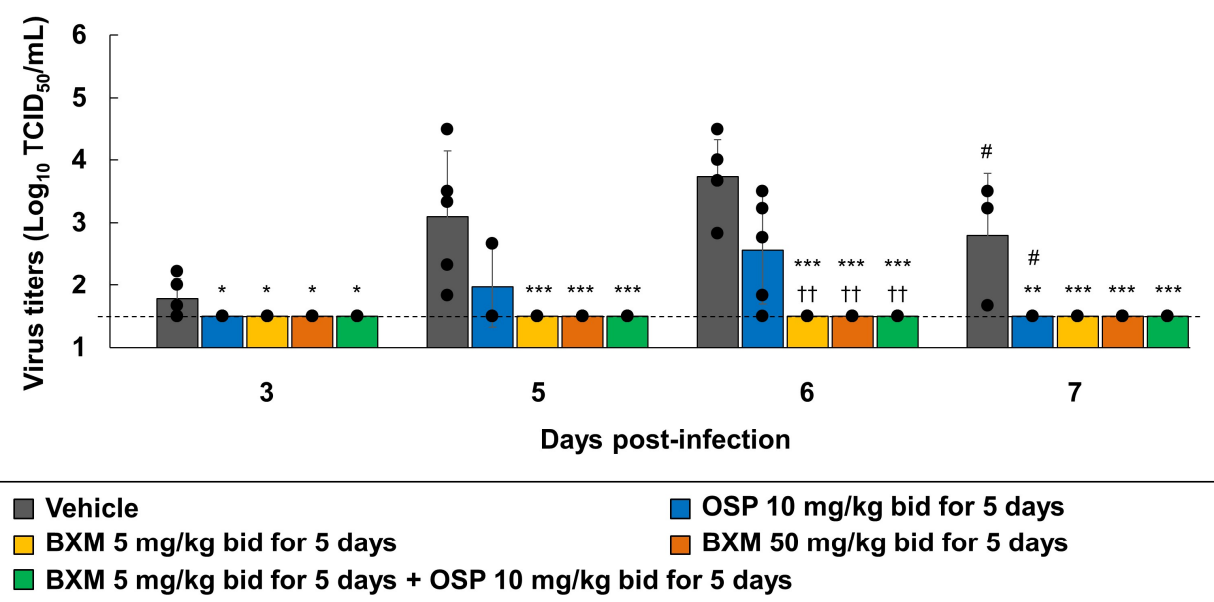

Figure 6. Inhibitory effects of delayed treatment of BXM, OSP or their combination on viral titers in the lungs, brains, and kidneys of mice infected with H5N1 HPAIV

Mice were intranasally infected with 75 TCID50/mouse (31.3 MLD50) of the A/Hong Kong/483/1997 (H5N1) virus, and treatment started $48 \mathrm{~h}$ after viral inoculation. Viral titers (TCID50) (a) in the lungs, (b) in the brains, and (c) in the kidneys of mice at 3, 5, 6, and 7 dpi measured in MDCK cells ( $n=5$ /group). The lower limit of quantification of the viral titer is indicated using a dotted line (1.5 $\log _{10}$ TCID $50 / \mathrm{mL}$ ). Dunnett's multiple-comparison method was conducted for statistical comparison between viral titers in each organ group $\left({ }^{*} p<0.05,{ }^{* *} p<0.01\right.$, ${ }^{* * *} p<0.001$ compared to vehicle, $\uparrow p<0.05,+\dagger p<0.01$, $++\dagger p<0.001$ compared to OSP at $10 \mathrm{mg} / \mathrm{kg}$ twice daily). $\#, \mathrm{n}=$ 3/group. 


\section{Discussion}

In this study, we presented the first experimental evidence that BXA exhibits similar in vitro activity against recent $\mathrm{H} 5 \mathrm{~N} 8$ variants or $\mathrm{H} 5 \mathrm{~N} 1$ viruses harboring NAI-resistant mutants than those of seasonal and other zoonotic strains for the experiment also tested therapeutic effects of oral BXM administration in an H5N1 HPAIV-infected murine model. Previous studies have shown that H5N1 HPAIVs have an overwhelming ability to replicate and spread in primary human immune cell cultures or multiple organs of mice or ferrets, unlike seasonal strains [52,53]. Therefore, it is meaningful to clarify the inhibitory efficacy of oral BXM dosing on the reduction of viral burden in multiple organs and assess mortality caused by H5N1 HPAIV infections in animal models. In our lethal A/Hong Kong/483/97 (H5N1)-infected mice model, 5-day dosing of BXM 5 mg/kg/dose was sufficient for significant decreases in viral burden of mice lungs, resulting in significant improvements in survival compared with those administered vehicle or OSP treatments.

In this model, viral replication in the brains or kidneys was detected by spillover caused by high viral replication in mice $[47,48]$. The systemic spread of the H5N1 viral strain has also been reported to be associated with disease pathogenesis in mammals, especially the A/Hong Kong/483/1997 (H5N1) strain, which accounted for neurotropism $[35,48,54,55]$. Similarly, few viruses have been detected in brains and kidneys after BXM treatment, suggesting that BXA directly inhibited viral replication in tissues other than the respiratory organs. Additionally, the antiviral efficacy of BXM has first been observed in the lungs, which is proposed to contribute to inhibition of viral spread from the lungs to extra respiratory organs. Nevertheless, the efficacy of this dosing regimen was similar to that in mice infected with other virus subtypes, H1N1 or H7N9 viruses [18,19]. This finding proposes that BXM treatment, using the extrapolated clinical setting from the above mice models, has therapeutic potentials against H5 HPAIVs, with high mortality being observed in mammals.

BXM and OSP combination therapy is a beneficial option for reducing viral titers in lungs and preventing death in severe H1N1 virus-infected mice model [16]. In this study, BXA and OSA combination showed synergistic effects in cell cultures. Combination therapy also increased the survival of mice compared to BXM- or OSP-monotherapy in a severe $\mathrm{H} 5 \mathrm{~N} 1$ virus-infected mice model, suggesting that combination therapy was efficient without antagonism on $\mathrm{H} 5 \mathrm{~N} 1$ virus infections. BXM and OSP have different modes of action on the viral replication cycle. Therefore, it is considered the combination therapy showed a strong viral inhibition and reduced systemic viral loads. Marathe and coworkers reported that combination therapy effects of the polymerase inhibitor; FPV, in addition to OSP, started $96 \mathrm{~h}$ after infection. A complete suppression of mortality in H5N1 virus-infected mice was also observed [24]. In our study, BXM and OSP combination started $48 \mathrm{~h}$ after infection and did not completely suppress mortality. This effect was proposed to be due to the higher infectivity of titers inoculated in our study compared with that of previous reports $[23,24]$. Nevertheless, our results are the first evidence confirming the combination efficacy of BXM and OSP for treating severe influenza like H5N1 HPAIV infection.

Elevated levels of proinflammatory cytokines have been detected in humans and mice infected with H5N1 HPAIV, virus-induced proinflammatory cytokines, and cases of chemokine dysregulation in the lungs and other tissues, which contribute to disease severity in clinical or non-clinical cases during H5N1 viral infections [10,36,56]. The production of IL-6 and MCP-1 in the early phase of H5N1 viral infections cause overinfiltration of monocytes or neutrophils in mice lungs of mice, thereby worsening respiratory functions $[57,58]$. Human H5N1 viral infections have also resulted in severe pneumonia, where most patients died due to ARDS [59]. Similar findings were observed in $\mathrm{H} 5 \mathrm{~N} 1$ virus-infected mice [44,60,61]. Similarly, our results showed that BXM treatment significantly decreased IL-6 and MCP-1 production and prevented increases in the lung wet weight-to-body weight ratios, which is consistent with the reduction of viral titers in the lungs. Furthermore, BXM treatment showed no histopathological changes, such as 
edema and hemorrhage in the lungs compared to those of the vehicle or OSP $5 \mathrm{mg} / \mathrm{kg}$ treatment groups, suggesting that BXM inhibited virus-triggered inflammation in the lungs. Additionally, in our model, although OSP showed inhibitory efficacy during lung inflammatory responses, the survival rate of mice was lower than that of those treated with BXM. OSP treatment, however, reduced lung inflammation, followed by a reduction in morbidity of seasonal influenza virus-infected mice although it did not reduce viral load [62]. This finding therefore suggests that OSP treatment immediately after viral infections suppressed lung inflammation and improved symptoms. However, the host cytokine response inhibition is insufficient for reducing morbidity and lethality of viral infections. A study has also reported that the early inhibition of viral replication is more promising than the inhibition of the cytokine response for improving host survival during H5N1 viral infections [63]. Moreover, the polymerase complex genes of human H5N1 virus strains contribute to high pathogenesis in mammals [64]. Some novel polymerase inhibitors (e.g., favipiravir and VX-787) have also shown strong efficacy at inhibiting viral replication, followed by preventing death in H5N1 virus-infected mice compared to OSP, implying that the inhibition of polymerase activity was effective in H5N1 virus infection $[65,66]$. Therefore, BXM, possessing greater potency at inhibiting viral RNA transcription, followed by inhibiting virus replication, is proposed to be more suitable as a therapeutic option than OSP.

In this study, no virus with mutations in PA or NA was detected in BXM or combined BXM and OSP-treated mice having H5N1 viral infections. However, it is unclear why the two variants were detected in the OSP-treated group. Results also showed that the threshold of coverage was ten-times that of the other samples, which is however proposed to influence these results. In clinical settings, the emergence of drug-resistant mutants in NA have been detected after NAI treatment with H5N1 HPAIV infections [28,29]. Moreover, a few natural occurrences in H5 HPAIV strains associated with reduced susceptibility to BXA were in the database [67]. Therefore, continuous virus monitoring and susceptibility testing of BXM is required.

\section{Conclusions}

This study demonstrated that BXA susceptibility to H5 HPAIV strains isolated over several years, including recently isolated $\mathrm{H} 5 \mathrm{~N} 8$ variants was retained. As observed, oral administration of BXM drastically decreased viral burdens in the lungs and extra respiratory organs. BXM administration also reduced lung inflammation and improved mortality in an H5N1 HPAIV-infected mice model. Moreover, combination therapy with BXM and OSP can be used as a treatment option for severe influenza-like H5 HPAIV infection. We also discovered that combination treatment had more potent effects on viral replication in organs, followed by an improvement in survival using a 48-hour-delayed treatment model compared with monotherapy. Furthermore, in our mouse models, no PA or NA variants was detected after BXM administration. Therefore, on the basis of these evidence, we propose that BXM has potent antiviral efficacy against H5 HPAIVs.

Author Contributions: Project design and data analysis by K.T., Y.A., M. Kobayashi, T.N., M. Kawai, R.Y., A.S., T. Shishido, and A.N.; interpretation by K.T., Y.A., T.N., A.S., T. Shishido, A.N., K.M., M.O., Y.S., and H.K.; in vitro study by K.T. and A.Y.; in vivo studies by K.T., Y.A., M. Kobayashi, S.T., H.N., and T. Sanaki, and manuscript written by K.T. All authors read and approved the manuscript.

Funding: This research received no external funding. 
Acknowledgments: We thank Richard J. Webby (St. Jude Children's Research Hospital, US) for generously providing A/ruddy turnstone/Delaware/103/2007 (H5N1). We also thank Takayuki Kuroda, Keiko Baba, Yuki Maruyama, and Kentaro Uemura (Shionogi \& Co., Ltd., Japan) for technical support. Furthermore, we thank Shinya Omoto, Satoshi Kojima, and Masahiro Kinoshita (Shionogi \& Co., Ltd., Japan) for preparing the manuscript.

Conflicts of Interest: The authors K.T., Y.A., H.N., S.T., T.N., T. Sanaki, M. Kawai, R.Y., A.S., T. Shishido, and A.N. are employees of Shionogi \& Co., Ltd. The authors K.M., M.O., Y.S., and H.K. were provided financial support from Shionogi \& Co., Ltd., for the studies conducted in the manuscript. The author M. Kobayashi, who was an employee of Shionogi \& Co., Ltd., declares no potential conflict of interest. Shionogi \& Co., Ltd financially supported all work reported in this study.

\section{References}

1. Centers for Disease Control and Prevention. Highly pathogenic asian avian influenza A (H5N1) virus Available online: https://www.cdc.gov/flu/avianflu/h5n1-virus.htm (accessed on 14 August 2021).

2. Lai, S.; Qin, Y.; Cowling, B.J.; Ren, X.; Wardrop, N.A.; Gilbert, M.; Tsang, T.K.; Wu, P.; Feng, L.; Jiang, H.; et al. Global epidemiology of avian influenza A H5N1 virus infection in humans, 1997-2015: a systematic review of individual case data. Lancet. Infect. Dis. 2016, 16, e108-e118, doi:10.1016/S1473-3099(16)00153-5.

3. Li, X.; Zhang, Z.; Yu, A.; Ho, S.Y.W.; Carr, M.J.; Zheng, W.; Zhang, Y.; Zhu, C.; Lei, F.; Shi, W. Global and local persistence of influenza A(H5N1) virus. Emerg. Infect. Dis. 2014, 20, 1287-1295, doi:10.3201/eid2008.130910.

4. Yang, L.; Zhao, X.; Li, X.; Bo, H.; Li, D.; Liu, J.; Wang, D. Case report for human infection with a highly pathogenic avian influenza A(H5N6) virus in Beijing, China 2019. Biosaf. Heal. 2020, 2, 49-52, doi:10.1016/j.bsheal.2020.02.003.

5. World Health Organization Human infection with avian influenza A (H5N8) - the Russian Federation Available online: https://www.who.int/csr/don/26-feb-2021-influenza-a-russian-federation/en/ (accessed on 14 August 2021).

6. McKenzie, D.K.; Butler, J.E.; Gandevia, S.C. Respiratory muscle function and activation in chronic obstructive pulmonary disease. J. Appl. Physiol. 2009, 107, 621-629, doi:10.1152/japplphysiol.00163.2009.

7. Peiris, J.S.M.; de Jong, M.D.; Guan, Y. Avian influenza virus (H5N1): a threat to human health. Clin. Microbiol. Rev. 2007, 20, 243-267, doi:10.1128/CMR.00037-06.

8. Hui, K.P.Y.; Lee, S.M.Y.; Cheung, C.; Ng, I.H.Y.; Poon, L.L.M.; Guan, Y.; Ip, N.Y.Y.; Lau, A.S.Y.; Peiris, J.S.M. Induction of proinflammatory cytokines in primary human macrophages by influenza a virus (H5N1) is selectively regulated by IFN regulatory factor 3 and p38 MAPK. J. Immunol. 2009, 182, 1088-1098, doi:10.4049/jimmunol.182.2.1088.

9. Wonderlich, E.R.; Swan, Z.D.; Bissel, S.J.; Hartman, A.L.; Carney, J.P.; O’Malley, K.J.; Obadan, A.O.; Santos, J.; Walker, R.; Sturgeon, T.J.; et al. Widespread Virus Replication in Alveoli Drives Acute Respiratory Distress Syndrome in Aerosolized H5N1 Influenza Infection of Macaques. J. Immunol. 2017, 198, 1616-1626, doi:10.4049/jimmunol.1601770.

10. de Jong, M.D.; Simmons, C.P.; Thanh, T.T.; Hien, V.M.; Smith, G.J.D.; Chau, T.N.B.; Hoang, D.M.; Chau, N.V.V.; Khanh, T.H.; Dong, V.C.; et al. Fatal outcome of human influenza A (H5N1) is associated with high viral load and hypercytokinemia. Nat. Med. 2006, 12, 1203-7, doi:10.1038/nm1477.

11. Kobayashi, M.; Kodama, M.; Noshi, T.; Yoshida, R.; Kanazu, T.; Nomura, N.; Soda, K.; Isoda, N.; Okamatsu, M.; Sakoda, Y.; et al. Therapeutic efficacy of peramivir against H5N1 highly pathogenic avian influenza viruses harboring the neuraminidase H275Y mutation. Antiviral Res. 2017, 139, 41-48, doi:10.1016/j.antiviral.2016.12.011.

12. Noshi, T.; Kitano, M.; Taniguchi, K.; Yamamoto, A.; Omoto, S.; Baba, K.; Hashimoto, T.; Ishida, K.; Kushima, Y.; Hattori, K.; et al. In vitro characterization of baloxavir acid, a first-in-class cap-dependent endonuclease inhibitor of the influenza virus polymerase PA subunit. Antiviral Res. 2018, 160, 109-117, doi:10.1016/j.antiviral.2018.10.008.

13. Omoto, S.; Speranzini, V.; Hashimoto, T.; Noshi, T.; Yamaguchi, H.; Kawai, M.; Kawaguchi, K.; Uehara, T.; Shishido, T.; Naito, A.; et al. Characterization of influenza virus variants induced by treatment with the endonuclease inhibitor baloxavir marboxil. Sci. Rep. 2018, 8, 9633, doi:10.1038/s41598-018-27890-4.

14. Mishin, V.P.; Patel, M.C.; Chesnokov, A.; De La Cruz, J.; Nguyen, H.T.; Lollis, L.; Hodges, E.; Jang, Y.; Barnes, J.; Uyeki, T.; et al. Susceptibility of influenza A, B, C, and D viruses to baloxavir1. Emerg. Infect. Dis. 2019, 25, 1969-1972, doi:10.3201/eid2510.190607.

15. Hayden, F.G.; Sugaya, N.; Hirotsu, N.; Lee, N.; de Jong, M.D.; Hurt, A.C.; Ishida, T.; Sekino, H.; Yamada, K.; Portsmouth, S.; et al. Baloxavir marboxil for uncomplicated influenza in adults and adolescents. N. Engl. J. Med. 2018, 379, 913-923, doi:10.1056/NEJMoa1716197.

16. Fukao, K.; Noshi, T.; Yamamoto, A.; Kitano, M.; Ando, Y.; Noda, T.; Baba, K.; Matsumoto, K.; Higuchi, N.; Ikeda, M.; et al. Combination treatment with the cap-dependent endonuclease inhibitor baloxavir marboxil and a neuraminidase inhibitor in a mouse model of influenza A virus infection. J. Antimicrob. Chemother. 2019, 74, 654-662, doi:10.1093/jac/dky462. 
17. Watanabe, A.; Ishida, T.; Hirotsu, N.; Kawaguchi, K.; Ishibashi, T.; Shishido, T.; Sato, C.; Portsmouth, S.; Tsuchiya, K.; Uehara, T. Baloxavir marboxil in Japanese patients with seasonal influenza: Dose response and virus type/subtype outcomes from a randomized phase 2 study. Antiviral Res. 2019, 163, 75-81, doi:10.1016/j.antiviral.2019.01.012.

18. Fukao, K.; Ando, Y.; Noshi, T.; Kitano, M.; Noda, T.; Kawai, M.; Yoshida, R.; Sato, A.; Shishido, T.; Naito, A. Baloxavir marboxil, a novel cap-dependent endonuclease inhibitor potently suppresses influenza virus replication and represents therapeutic effects in both immunocompetent and immunocompromised mouse models. PLoS One 2019, 14, e0217307, doi:10.1371/journal.pone.0217307.

19. Taniguchi, K.; Ando, Y.; Nobori, H.; Toba, S.; Noshi, T.; Kobayashi, M.; Kawai, M.; Yoshida, R.; Sato, A.; Shishido, T.; et al. Inhibition of avian-origin influenza A(H7N9) virus by the novel cap-dependent endonuclease inhibitor baloxavir marboxil. Sci. Rep. 2019, 9, 3466, doi:10.1038/s41598-019-39683-4.

20. Ikematsu, H.; Hayden, F.G.; Kawaguchi, K.; Kinoshita, M.; de Jong, M.D.; Lee, N.; Takashima, S.; Noshi, T.; Tsuchiya, K.; Uehara, T. Baloxavir marboxil for prophylaxis against influenza in household contacts. N. Engl. J. Med. 2020, 383, 309-320, doi:10.1056/NEJMoa1915341.

21. Wang, Y.; Fan, G.; Salam, A.; Horby, P.; Hayden, F.G.; Chen, C.; Pan, J.; Zheng, J.; Lu, B.; Guo, L.; et al. Comparative effectiveness of combined favipiravir and oseltamivir therapy versus oseltamivir monotherapy in critically ill patients with influenza virus infection. J. Infect. Dis. 2020, 221, 1688-1698, doi:10.1093/infdis/jiz656.

22. Yoshimura, Y.; Sasaki, H.; Horiuchi, H.; Miyata, N.; Kawakami, C.; Usuku, S.; Tachikawa, N. Early combination treatment with baloxavir and peramivir for hospitalized adults with influenza A in Yokohama, Japan. Eur. J. Clin. Microbiol. Infect. Dis. 2020, 39, 1637-1640, doi:10.1007/s10096-020-03888-7.

23. Smee, D.F.; Hurst, B.L.; Wong, M.-H.; Bailey, K.W.; Tarbet, E.B.; Morrey, J.D.; Furuta, Y. Effects of the combination of favipiravir (T-705) and oseltamivir on influenza A virus infections in mice. Antimicrob. Agents Chemother. 2010, 54, 126-133, doi:10.1128/AAC.00933-09.

24. Marathe, B.M.; Wong, S.-S.; Vogel, P.; Garcia-Alcalde, F.; Webster, R.G.; Webby, R.J.; Najera, I.; Govorkova, E.A. Combinations of oseltamivir and T-705 extend the treatment window for highly pathogenic influenza A(H5N1) virus infection in mice. Sci. Rep. 2016, 6, 26742, doi:10.1038/srep26742.

25. Ilyushina, N.A.; Hoffmann, E.; Salomon, R.; Webster, R.G.; Govorkova, E.A. Amantadine-oseltamivir combination therapy for H5N1 influenza virus infection in mice. Antivir. Ther. 2007, 12, 363-370.

26. Govorkova, E.A.; Leneva, I.A.; Goloubeva, O.G.; Bush, K.; Webster, R.G. Comparison of efficacies of RWJ-270201, zanamivir, and oseltamivir against H5N1, H9N2, and other avian influenza viruses. Antimicrob. Agents Chemother. 2001, 45, 2723-2732, doi:10.1128/AAC.45.10.2723-2732.2001.

27. Liem, N.T.; Tung, C.V.; Hien, N.D.; Hien, T.T.; Chau, N.Q.; Long, H.T.; Hien, N.T.; Mai, L.Q.; Taylor, W.R.J.; Wertheim, H.; et al. Clinical features of human influenza A (H5N1) infection in Vietnam: 2004-2006. Clin. Infect. Dis. 2009, 48, 1639-1646, doi:10.1086/599031.

28. de Jong, M.D.; Tran, T.T.; Truong, H.K.; Vo, M.H.; Smith, G.J.D.; Nguyen, V.C.; Bach, V.C.; Phan, T.Q.; Do, Q.H.; Guan, Y.; et al. Oseltamivir resistance during treatment of influenza A (H5N1) infection. N. Engl. J. Med. 2005, 353, 2667-2672, doi:10.1056/NEJMoa054512.

29. Karthick, V.; Ramanathan, K. Insight into the oseltamivir resistance R292K mutation in H5N1 influenza virus: a molecular docking and molecular dynamics approach. Cell Biochem. Biophys. 2014, 68, 291-299, doi:10.1007/s12013-013-9709-2.

30. Govorkova, E.A.; Baranovich, T.; Seiler, P.; Armstrong, J.; Burnham, A.; Guan, Y.; Peiris, M.; Webby, R.J.; Webster, R.G. Antiviral resistance among highly pathogenic influenza A (H5N1) viruses isolated worldwide in 2002-2012 shows need for continued monitoring. Antiviral Res. 2013, 98, 297-304, doi:10.1016/j.antiviral.2013.02.013.

31. Schaduangrat, N.; Phanich, J.; Rungrotmongkol, T.; Lerdsamran, H.; Puthavathana, P.; Ubol, S. The significance of naturally occurring neuraminidase quasispecies of $\mathrm{H} 5 \mathrm{~N} 1$ avian influenza virus on resistance to oseltamivir: a point of concern. J. Gen. Virol. 2016, 97, 1311-1323, doi:10.1099/jgv.0.000444.

32. Uehara, T.; Hayden, F.G.; Kawaguchi, K.; Omoto, S.; Hurt, A.C.; De Jong, M.D.; Hirotsu, N.; Sugaya, N.; Lee, N.; Baba, K.; et al. Treatment-emergent influenza variant viruses with reduced baloxavir susceptibility: impact on clinical and virologic outcomes in uncomplicated influenza. J. Infect. Dis. 2019, 221, 346-355, doi:10.1093/infdis/jiz244.

33. Takashita, E.; Morita, H.; Ogawa, R.; Nakamura, K.; Fujisaki, S.; Shirakura, M.; Kuwahara, T.; Kishida, N.; Watanabe, S.; Odagiri, T. Susceptibility of influenza viruses to the novel cap-dependent endonuclease inhibitor baloxavir marboxil. Front. Microbiol. 2018, 9, 3026, doi:10.3389/fmicb.2018.03026.

34. Takashita, E.; Abe, T.; Morita, H.; Nagata, S.; Fujisaki, S.; Miura, H.; Shirakura, M.; Kishida, N.; Nakamura, K.; Kuwahara, T.; et al. Influenza A(H1N1)pdm09 virus exhibiting reduced susceptibility to baloxavir due to a PA E23K substitution detected from a child without baloxavir treatment. Antiviral Res. 2020, 180, 104828, doi:10.1016/j.antiviral.2020.104828.

35. Nishimura, H.; Itamura, S.; Iwasaki, T.; Kurata, T.; Tashiro, M. Characterization of human influenza A (H5N1) virus infection in mice: neuro-, pneumo- and adipotropic infection. J. Gen. Virol. 2000, 81, 2503-2510, doi:10.1099/0022-1317-81-10-2503.

36. Tumpey, T.M.; Lu, X.; Morken, T.; Zaki, S.R.; Katz, J.M. Depletion of lymphocytes and diminished cytokine production in mice infected with a highly virulent influenza A (H5N1) virus isolated from humans. J. Virol. 2000, 74, 6105-6116, doi:10.1128/jvi.74.13.6105-6116.2000.

37. Shichinohe, S.; Okamatsu, M.; Yamamoto, N.; Noda, Y.; Nomoto, Y.; Honda, T.; Takikawa, N.; Sakoda, Y.; Kida, H. Potency of an inactivated influenza vaccine prepared from a non-pathogenic H5N1 virus against a challenge with antigenically drifted highly pathogenic avian influenza viruses in chickens. Vet. Microbiol. 2013, 164, 39-45, doi:10.1016/j.vetmic.2013.01.041. 
38. Sakoda, Y.; Sugar, S.; Batchluun, D.; Erdene-Ochir, T.-O.; Okamatsu, M.; Isoda, N.; Soda, K.; Takakuwa, H.; Tsuda, Y.; Yamamoto, N.; et al. Characterization of H5N1 highly pathogenic avian influenza virus strains isolated from migratory waterfowl in Mongolia on the way back from the southern Asia to their northern territory. Virology 2010, 406, 88-94, doi:10.1016/j.virol.2010.07.007.

39. Hiono, T.; Okamatsu, M.; Matsuno, K.; Haga, A.; Iwata, R.; Nguyen, L.T.; Suzuki, M.; Kikutani, Y.; Kida, H.; Onuma, M.; et al. Characterization of H5N6 highly pathogenic avian influenza viruses isolated from wild and captive birds in the winter season of 2016-2017 in Northern Japan. Microbiol. Immunol. 2017, 61, 387-397, doi:10.1111/1348-0421.12506.

40. Isoda, N.; Twabela, A.T.; Bazarragchaa, E.; Ogasawara, K.; Hayashi, H.; Wang, Z.-J.; Kobayashi, D.; Watanabe, Y.; Saito, K.; Kida, H.; et al. Re-invasion of H5N8 high pathogenicity avian influenza virus clade 2.3.4.4b in Hokkaido, Japan, 2020. Viruses 2020, 12, 1439, doi:10.3390/v12121439.

41. Hoffmann, E.; Neumann, G.; Kawaoka, Y.; Hobom, G.; Webster, R.G. A DNA transfection system for generation of influenza A virus from eight plasmids. Proc. Natl. Acad. Sci. U. S. A. 2000, 97, 6108-6113, doi:10.1073/pnas.100133697.

42. Ward, P.; Small, I.; Smith, J.; Suter, P.; Dutkowski, R. Oseltamivir (Tamiflu) and its potential for use in the event of an influenza pandemic. J. Antimicrob. Chemother. 2005, 55 Suppl 1, i5-i21, doi:10.1093/jac/dki018.

43. Nomura, N.; Matsuno, K.; Shingai, M.; Ohno, M.; Sekiya, T.; Omori, R.; Sakoda, Y.; Webster, R.G.; Kida, H. Updating the influenza virus library at Hokkaido University -It's potential for the use of pandemic vaccine strain candidates and diagnosis. Virology 2021, 557, 55-61, doi:10.1016/j.virol.2021.02.005.

44. Qiao, J.; Zhang, M.; Bi, J.; Wang, X.; Deng, G.; He, G.; Luan, Z.; Lv, N.; Xu, T.; Zhao, L. Pulmonary fibrosis induced by H5N1 viral infection in mice. Respir. Res. 2009, 10, 107, doi:10.1186/1465-9921-10-107.

45. Nobori, H.; Toba, S.; Yoshida, R.; Hall, W.W.; Orba, Y.; Sawa, H.; Sato, A. Identification of compound-B, a novel anti-dengue virus agent targeting the non-structural protein 4A. Antiviral Res. 2018, 155, 60-66, doi:10.1016/j.antiviral.2018.05.003.

46. Earhart, K.C.; Elsayed, N.M.; Saad, M.D.; Gubareva, L. V.; Nayel, A.; Deyde, V.M.; Abdelsattar, A.; Abdelghani, A.S.; Boynton, B.R.; Mansour, M.M.; et al. Oseltamivir resistance mutation N294S in human influenza A(H5N1) virus in Egypt. J. Infect. Public Health 2009, 2, 74-80, doi:10.1016/j.jiph.2009.04.004.

47. Park, C.H.; Ishinaka, M.; Takada, A.; Kida, H.; Kimura, T.; Ochiai, K.; Umemura, T. The invasion routes of neurovirulent A/Hong Kong/483/97 (H5N1) influenza virus into the central nervous system after respiratory infection in mice. Arch. Virol. 2002, 147, 1425-1436, doi:10.1007/s00705-001-0750-x.

48. Lu, X.; Tumpey, T.M.; Morken, T.; Zaki, S.R.; Cox, N.J.; Katz, J.M. A mouse model for the evaluation of pathogenesis and immunity to influenza A (H5N1) viruses isolated from humans. J. Virol. 1999, 73, 5903-5911, doi:10.1128/JVI.73.7.5903-5911.1999.

49. Maines, T.R.; Lu, X.H.; Erb, S.M.; Edwards, L.; Guarner, J.; Greer, P.W.; Nguyen, D.C.; Szretter, K.J.; Chen, L.-M.; Thawatsupha, P.; et al. Avian influenza (H5N1) viruses isolated from humans in Asia in 2004 exhibit increased virulence in mammals. J. Virol. 2005, 79, 11788-11800, doi:10.1128/JVI.79.18.11788-11800.2005.

50. Checkmahomed, L.; Padey, B.; Pizzorno, A.; Terrier, O.; Rosa-Calatrava, M.; Abed, Y.; Baz, M.; Boivin, G. In vitro combinations of baloxavir acid and other inhibitors against seasonal influenza A viruses. Viruses 2020, 12, 1139, doi:10.3390/v12101139.

51. Flannery, A.H.; Thompson Bastin, M.L. Oseltamivir dosing in critically ill patients with severe influenza. Ann. Pharmacother. 2014, 48, 1011-1018, doi:10.1177/1060028014535362.

52. Westenius, V.; Mäkelä, S.M.; Julkunen, I.; Österlund, P. Highly pathogenic H5N1 influenza A virus spreads efficiently in human primary monocyte-derived macrophages and dendritic cells. Front. Immunol. 2018, 9, 1664, doi:10.3389/fimmu.2018.01664.

53. Plourde, J.R.; Pyles, J.A.; Layton, R.C.; Vaughan, S.E.; Tipper, J.L.; Harrod, K.S. Neurovirulence of H5N1 infection in ferrets is mediated by multifocal replication in distinct permissive neuronal cell regions. PLoS One 2012, 7, e46605, doi:10.1371/journal.pone.0046605.

54. Zitzow, L.A; Rowe, T.; Morken, T.; Shieh, W.-J.; Zaki, S.; Katz, J.M. Pathogenesis of avian influenza A (H5N1) viruses in ferrets. J. Virol. 2002, 76, 4420-4429, doi:10.1128/JVI.76.9.4420.

55. Rimmelzwaan, G.F.; Kuiken, T.; van Amerongen, G.; Bestebroer, T.M.; Fouchier, R.A.; Osterhaus, A.D. Pathogenesis of influenza A (H5N1) virus infection in a primate model. J. Virol. 2001, 75, 6687-6691, doi:10.1128/JVI.75.14.6687-6691.2001.

56. Szretter, K.J.; Gangappa, S.; Lu, X.; Smith, C.; Shieh, W.-J.; Zaki, S.R.; Sambhara, S.; Tumpey, T.M.; Katz, J.M. Role of host cytokine responses in the pathogenesis of avian H5N1 influenza viruses in mice. J. Virol. 2007, 81, 2736-2744, doi:10.1128/JVI.02336-06.

57. Spesock, A.; Malur, M.; Hossain, M.J.; Chen, L.-M.; Njaa, B.L.; Davis, C.T.; Lipatov, A.S.; York, I.A.; Krug, R.M.; Donis, R.O. The virulence of $1997 \mathrm{H} 5 \mathrm{~N} 1$ influenza viruses in the mouse model is increased by correcting a defect in their NS1 proteins. J. Virol. 2011, 85, 7048-7058, doi:10.1128/JVI.00417-11.

58. Perrone, L.A.; Plowden, J.K.; García-Sastre, A.; Katz, J.M.; Tumpey, T.M. H5N1 and 1918 pandemic influenza virus infection results in early and excessive infiltration of macrophages and neutrophils in the lungs of mice. PLoS Pathog. 2008, 4, e1000115, doi:10.1371/journal.ppat.1000115.

59. Luo, H.; Wang, D.; Che, H.-L.; Zhao, Y.; Jin, H. Pathological observations of lung inflammation after administration of IP-10 in influenza virus- and respiratory syncytial virus-infected mice. Exp. Ther. Med. 2012, 3, 76-79, doi:10.3892/etm.2011.350.

60. Xu, T.; Qiao, J.; Zhao, L.; Wang, G.; He, G.; Li, K.; Tian, Y.; Gao, M.; Wang, J.; Wang, H.; et al. Acute respiratory distress syndrome induced by avian influenza A (H5N1) virus in mice. Am. J. Respir. Crit. Care Med. 2006, 174, 1011-1017, doi:10.1164/rccm.2005111751OC.

61. Ogiwara, H.; Yasui, F.; Munekata, K.; Takagi-Kamiya, A.; Munakata, T.; Nomura, N.; Shibasaki, F.; Kuwahara, K.; Sakaguchi, N.; Sakoda, Y.; et al. Histopathological evaluation of the diversity of cells susceptible to H5N1 virulent avian influenza virus. Am. J. Pathol. 2014, 184, 171-183, doi:10.1016/j.ajpath.2013.10.004. 
62. Bird, N.L.; Olson, M.R.; Hurt, A.C.; Oshansky, C.M.; Oh, D.Y.; Reading, P.C.; Chua, B.Y.; Sun, Y.; Tang, L.; Handel, A.; et al. Oseltamivir prophylaxis reduces inflammation and facilitates establishment of cross-strain protective $\mathrm{T}$ cell memory to influenza viruses. PLoS One 2015, 10, e0129768, doi:10.1371/journal.pone.0129768.

63. Salomon, R.; Hoffmann, E.; Webster, R.G. Inhibition of the cytokine response does not protect against lethal H5N1 influenza infection. Proc. Natl. Acad. Sci. U. S. A. 2007, 104, 12479-12481, doi:10.1073/pnas.0705289104.

64. Salomon, R.; Franks, J.; Govorkova, E.A.; Ilyushina, N.A.; Yen, H.-L.; Hulse-Post, D.J.; Humberd, J.; Trichet, M.; Rehg, J.E.; Webby, R.J.; et al. The polymerase complex genes contribute to the high virulence of the human H5N1 influenza virus isolate A/Vietnam/1203/04. J. Exp. Med. 2006, 203, 689-697, doi:10.1084/jem.20051938.

65. Byrn, R.A.; Jones, S.M.; Bennett, H.B.; Bral, C.; Clark, M.P.; Jacobs, M.D.; Kwong, A.D.; Ledeboer, M.W.; Leeman, J.R.; McNeil, C.F.; et al. Preclinical activity of VX-787, a first-in-class, orally bioavailable inhibitor of the influenza virus polymerase PB2 subunit. Antimicrob. Agents Chemother. 2015, 59, 1569-1582, doi:10.1128/AAC.04623-14.

66. Kiso, M.; Takahashi, K.; Sakai-Tagawa, Y.; Shinya, K.; Sakabe, S.; Le, Q.M.; Ozawa, M.; Furuta, Y.; Kawaoka, Y. T-705 (favipiravir) activity against lethal H5N1 influenza A viruses. Proc. Natl. Acad. Sci. U. S. A. 2010, 107, 882-887, doi:10.1073/pnas.0909603107.

67. Svyatchenko, S. V.; Goncharova, N.I.; Marchenko, V.Y.; Kolosova, N.P.; Shvalov, A.N.; Kovrizhkina, V.L.; Durymanov, A.G.; Onkhonova, G.S.; Tregubchak, T. V.; Susloparov, I.M.; et al. An influenza A(H5N8) virus isolated during an outbreak at a poultry farm in Russia in 2017 has an N294S substitution in the neuraminidase and shows reduced susceptibility to oseltamivir. Antiviral Res. 2021, 191, 105079, doi:10.1016/j.antiviral.2021.105079. 